\title{
Lentiviral Vector-mediated Gene Transfer in Human Bladder Cancer Cell Lines
}

\author{
WATARU MATSUNAGA ${ }^{1}$, MISA ICHIKAWA ${ }^{1,2}$, AZUMI NAKAMURA $^{1}$, \\ TAKAHIRO ISHIKAWA ${ }^{1,2}$ and AKINOBU GOTOH ${ }^{1}$ \\ ${ }^{1}$ Laboratory of Cell and Gene Therapy, Institute for Advanced Medical Sciences, \\ Hyogo College of Medicine, Nishinomiya, Japan; \\ ${ }^{2}$ Sentan Bio Medical Laboratory, Tokyo, Japan
}

\begin{abstract}
Background/Aim: Currently, treatment of non-muscle invasive bladder cancer causes significant deterioration in a patient's quality of life ( $Q O L)$. Therefore, development of novel therapeutic options without the deterioration of QOL is very important. In this study, we assessed the anti-tumor effect of lentivirus-mediated gene transfection of tumor-suppressor genes in human bladder cancer cells. Materials and Methods: Lentiviral vectors that contained the tumor suppressor genes, p53, p16, and PTEN, were transfected into human bladder cancer cell lines, 5637, T24, 253J, and UMUC3, and the normal human uroepithelial cell line, SV-HUC-1. Results: Significant growth inhibition was observed in bladder cancer cells on transfection with the p16 and PTEN vectors. However, the effect of the p53 vector was limited. In normal cells, the lentiviral vectors did not exhibit a significant growth inhibitory effect. Conclusion: Lentiviral vector-mediated gene transfection is useful for the application of gene therapy in bladder cancers.
\end{abstract}

Most bladder cancers are non-muscle invasive bladder cancers (NMIBC), and are found in over $70 \%$ of patients. NMIBC is generally treated via transurethral resection of the tumor, followed by intravesical administration of the anticancer agent (1). However, most NMIBC cases develop recurrent tumors and progress to a higher stage or grade (1). Bladder cancer presents with relatively low incidence and mortality in Japan, accounting for 30.3 new cases and 13.1 deaths per 100,000 individuals (2). However, NMIBC remains a crucial issue because of its high recurrence rate.

This article is freely accessible online.

Correspondence to: Akinobu Gotoh, Laboratory of Cell and Gene Therapy, Institute for Advanced Medical Sciences, Hyogo College of Medicine, 1-1 Mukogawa-cho, Nishinomiya 663-8501, Japan. Tel: +81 798456807, Fax: +81 798456806, e-mail: gotoh@hyo-med.ac.jp

Key Words: Lentivirus, p53, p16, PTEN, bladder cancer.
Currently, Bacillus Calmette-Guérin (BCG) therapy is thought to be the most effective therapy against refractory NMIBC. However, it requires frequent intravesical injection, becoming a source of distress and burden to patients. Moreover, strong and unpleasant adverse effects occur in almost every patient after receiving the BCG injection, causing significant deterioration of a patient's quality of life (QOL) (3). In fact, many patients abandon BCG therapy with adverse effects; hence, the completion rate of the therapy is only 50\% in Japan (4). Therefore, development of new treatments that do not reduce the patient's QOL is very important in treating NMIBC.

Viral gene therapy may effectively treat NMIBC without seriously deteriorating patient QOL. Recently, studies on the adenoviral transfection of various genes were performed in bladder cancer cells $(5,6)$. However, adenoviral vectors were found to have certain disadvantages, such as transient gene expression, high immune response, and cytotoxicity of the virus particle. Our recent study reported low expression levels of adenovirus receptors (coxsackie and adenovirus receptor) in high-grade bladder cancer cells (7). Therefore, using adenoviral vectors to treat NMIBC is believed to require frequent administration and cause unpleasant side effects that are caused by the cytotoxicity of virus particle. However, lentivirus-mediated gene transfection showed long-term gene expression without any cytotoxicity. Therefore, we considered lentiviral vectors to be more suitable in treating NMIBC than adenoviral vectors.

In this study, we examined 3 tumor suppressor genes i.e., tumor protein 53 (p53), pl6, and phosphatase and tensin homolog deleted on chromosome 10 (PTEN).

$p 53$ gene is a classical and typical tumor suppressor gene, and its protein is known as "the guardian of the genome". Mutation of the $p 53$ gene or functional inactivation of the $\mathrm{p} 53$ protein leads to apoptotic resistance in cancer cells. Abnormality in $p 53$ gene expression or functional inactivation of the p53-related signaling pathway occurs in over $50 \%$ of cancers, including bladder cancer (8). Therefore, p53 is an attractive target for gene therapies in cancers (9). 


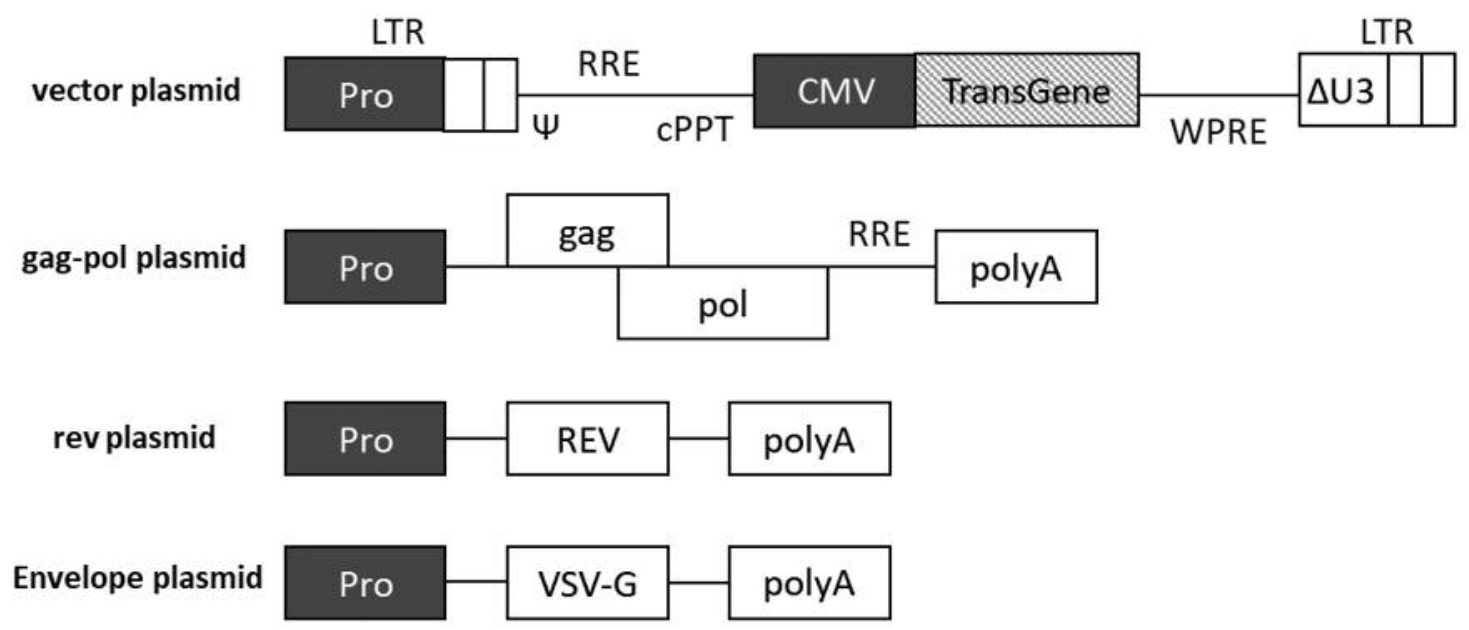

Figure 1. The 4 plasmids used to construct lentiviral vectors. $\Psi$ : Packaging signal, RRE: rev-responsive element, cPPT: central polypurine tract, WPRE: woodchuck hepatitis virus posttranscriptional regulatory element, VSV-G: glycoprotein of the vesicular stomatitis virus, CMV: cytomegalovirus promoter.

p16 (also known as p14, p16/ink4a, ink4a, or Cyclindependent kinase inhibitor $2 \mathrm{~A}$ ) is a cyclin-dependent kinase (CDK) inhibitor that plays an important role in the regulation of the cell cycle $(10,11)$. It also functions as a tumor suppressor by inhibiting CDK4/6 (12). Similar to $p 53$, p16 gene mutation can also be observed in many cancers, particularly in about $50 \%$ of bladder cancers (13). Thus, we believe $p 16$ to be a promising target for gene therapy in NMIBC.

The PTEN gene is also known to be a tumor suppressor gene (14). Mutation of the PTEN gene has been reported in various tumors $(15,16)$, and $P T E N$ gene or protein abnormality was observed in about $50 \%$ of cancers (17). The PTEN protein functions as a tumor suppressor by negatively regulating the PI3K/Akt pathway via dephosphorylation of phosphatidylinositol-3,4,5-trisphosphate (18). PTEN mutation is relatively rare in human bladder cancers $(19,20)$; however, previous studies that reported adenovirus-mediated PTEN gene therapy on human urological cancer cells demonstrated promising anti-tumor effects $(21,22)$. Therefore, we also included the PTEN gene in this study.

These tumor suppressor genes ( $p 53, p 16$, and PTEN) have been thoroughly studied with respect to gene therapy in various cancers; however, lentivirus-mediated transfection has not yet been performed. Here, we report the in vitro effect of lentiviral vectors carrying tumor suppressor genes on the viability of bladder cancer cells.

\section{Materials and Methods}

Lentiviral vectors. In this study, we used third-generation recombinant HIV-1-based self-inactivating lentiviral vectors. These lentiviral vectors were generated by co-transfecting $293 \mathrm{~T}$ cells with 4 plasmids
Table I. Histopathological grade and mutation status of the bladder cancer cells used in this study.

\begin{tabular}{lcccc}
\hline Cell line & Grade & p531,2 & p161,2 & PTEN $^{1,2}$ \\
\hline 5637 & II & Mutation & WT & WT \\
UMUC3 & & Mutation & WT/Mutation* & Mutation \\
T24 & III & Mutation & WT/Mutation* & Mutation** \\
253J & IV & WT & Mutation & WT \\
\hline
\end{tabular}

${ }^{1}$ COSMIC database (http://cancer.sanger.ac.uk/cosmic), ${ }^{2}$ Earl et al., 2015 (28), 3Platt et al., 2009 (33), *p16 gene mutation is not reported in the COSMIC Database for these cell lines, but Earl et al., reported mutation, **Mutation status is N48I (50), but protein expression is observed in the T24 cell line.

(vector plasmid, gag-pol plasmid, rev plasmid, and envelope plasmid pseudotyped with glycoprotein of the vesicular stomatitis virus). The vector plasmids were constructed with 3 types of tumor suppressor genes that expressed human $p 53$ (Lenti-p53), human PTEN (LentiPTEN), and human p16 (Lenti-p16), driven by the Cytomegalovirus promoter (Figure 1).

After transfection and culture for $48 \mathrm{~h}$, the medium containing the lentiviral vectors was obtained and concentrated via ultracentrifugation ( 2 rounds of $50,000 \times g$ for $2 \mathrm{~h}$ ). The titer of vectors was determined by measuring the amount of p24 capsid protein using an ELISA kit (Rimco Corporation, Uruma, Japan). The titers of the lentiviral vectors were observed to be $5.0 \times 10^{7}$ transduction units $/ \mathrm{ml}(\mathrm{TU} / \mathrm{ml})$.

Cell lines and cell culture. In this study, 4 human bladder cancer cell lines, 5637, UMUC3, T24, and 253J, and one normal human uroepithelial cell line, SV-HUC-1, were used. These cell lines were purchased from the American Type Culture Collection (ATCC, Manassas, VA, USA). The characteristics of the cancer cell lines have already been reported and are detailed in Table I. The 5637 cells were 


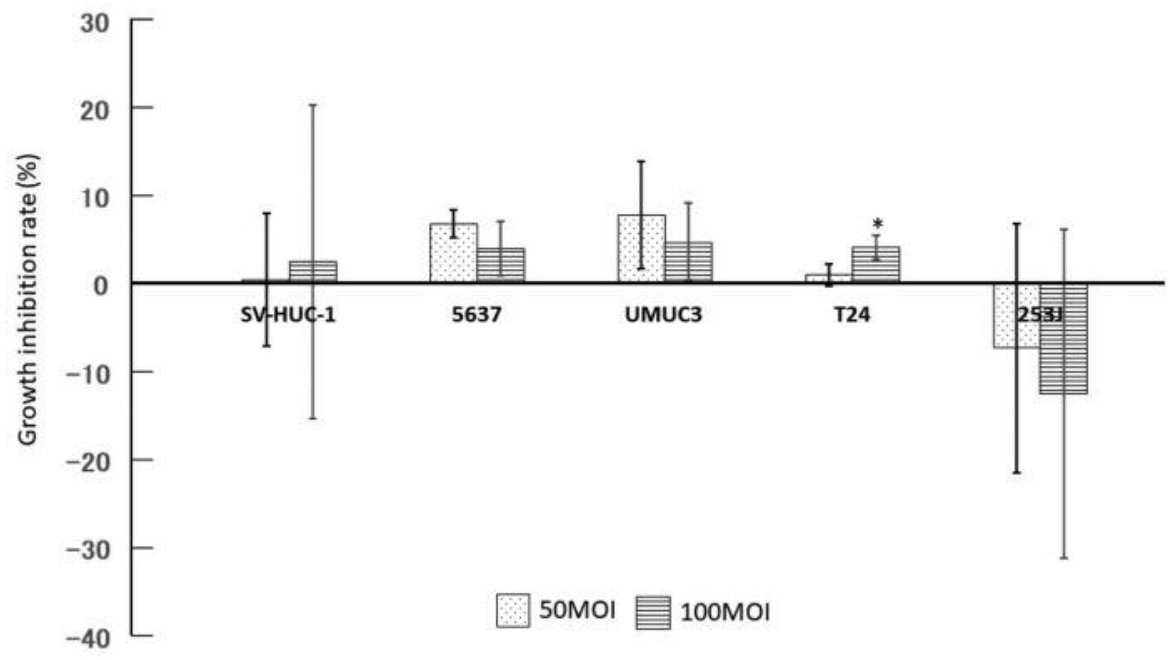

Figure 2. Cell growth inhibition rate of each cell line 96 h after p53 vector infection. Significant growth inhibition was not observed in the experimental cells, except in T24. The data represents the mean \pm S.E. of the mean percentage $(0 \%=$ cell inhibition rate of uninfected cells $) . N=3-5, * p<0.05$.

grown in Roswell Park Memorial Institute 1640 (RPMI1640; Life Technologies Co., NY, USA) medium and the other cell lines were grown in Dulbecco's Modified Eagle's Medium (DMEM; Life Technologies Co., NY, USA). Both media were supplemented with $10 \%$ heat-inactivated fetal bovine serum (FBS; BioWest, Nuaillé, France) and $100 \mathrm{U} / \mathrm{ml}$ of penicillin-streptomycin (Nacalai Tesque Inc., Kyoto, Japan). The cultures were maintained in humidified $5 \% \mathrm{CO}_{2}$ and $95 \%$ air at $37^{\circ} \mathrm{C}$.

Infection with lentiviral vectors. Lentiviral vector infection was performed at 50 and 100 multiplicity of infection (MOI), and we considered that number of cells $/ \mathrm{ml} \times \mathrm{MOI}=\mathrm{TU} / \mathrm{ml}$.

The experimental cells were diluted to 60,000 cells $/ \mathrm{ml}$ in each growth medium. Each lentiviral vector was dissolved in serum-free RPMI1640 or DMEM for $6.0 \times 10^{6} \mathrm{TU} / \mathrm{ml}$ and $1.2 \times 10^{7} \mathrm{TU} / \mathrm{ml}$. Infection with the lentiviral vectors was performed in the mixtures containing equal amounts of cell suspension and dissolved lentiviral vectors (final concentration is $50 \mathrm{MOI}$ and $100 \mathrm{MOI}$ for $30,000 \mathrm{cells} / \mathrm{ml}$ ). To improve the infection efficiency, we used a modified spinfection method where the mixtures were centrifuged at $1200 \times g$ for $1 \mathrm{~h}$ at $32^{\circ} \mathrm{C}(23)$. The cells were then seeded into 96-well plates $(3,000$ cells/well, 5\% FBS containing medium) and incubated in $5 \% \mathrm{CO}_{2}$ and $95 \%$ air at $37^{\circ} \mathrm{C}$. After infection for $24 \mathrm{~h}$, the medium was replaced with fresh medium containing 5\% FBS and further incubated for $72 \mathrm{~h}$.

Measuring the cell growth inhibition rate. The growth inhibition rate of each cell was measured via the 3-(4,5-dimethylthiazol-2-yl)-2,5diphenyltetrazolium bromide (MTT) assay. After $96 \mathrm{~h}$ of lentiviral vector infection, $250 \mu \mathrm{g} / \mathrm{ml}$ of MTT (Dojin Kagaku, Kumamoto, Japan) was dissolved in serum-free DMEM or RPMI1640, which was used to replace the 96-well plate incubation medium (100 $\mu \mathrm{l} /$ well), and further incubated at $37^{\circ} \mathrm{C}$ in $5 \% \mathrm{CO}_{2}$ and $95 \%$ air for $4 \mathrm{~h}$. The stop solution (20\% SDS and 50\% N, N-Dimethylformamide containing $0.04 \mathrm{M} \mathrm{HCl})$ was added to each well $(100 \mu \mathrm{l} /$ well $)$ and incubated overnight at RT with mechanical shaking. The cell viability was assessed via the MTT assay using SpectraMax ${ }^{\circledR}$ Plus 384 (Molecular Devices, CA, USA) as described previously (24). The percentage of cell growth inhibition rate was calculated from the following absorbance measurements: An, negative control (no cells); Ac, positive control cells (mean absorbance of non-infected cells: $0 \%$ of growth inhibition); and Ax, lentiviral vector-treated cells. They were then applied in the following equation: $100-((\mathrm{Ax}-\mathrm{An}) /(\mathrm{Ac}-\mathrm{An}) \times 100)$.

Statistical analysis. All the data were analyzed using the JSTAT ver. 22.0J software (free ware), and the results were expressed as mean \pm standard error (S.E.). Statistical comparisons between the different MOIs of the vectors against each respective cell line were performed using a one-way ANOVA followed by the Tukey's post$h o c$ test. Differences were considered to be significant when $p<0.05$.

\section{Results}

In this study, the growth inhibitory effect of lentiviral vectors was measured via the MTT assay. The cell growth inhibition rate was assessed $96 \mathrm{~h}$ after infection.

Effect of Lenti-p53. Lenti-p53 did not exhibit a significant effect on cell inhibition, except in T24 cells (Figure 2). However, the effect of Lenti-p53 on T24 was limited, and the growth inhibition rate was observed to be $4.133 \%$ at $100 \mathrm{MOI}$ $(f(13,2)=4.140, p=0.046)$. The other bladder cancer cells and SV-HUC-1 cells did not exhibit significant changes after Lenti-p53 infection.

Effect of Lenti-p16. Lenti-p16 exhibited a significant effect on the cell growth of T24, 253J, and UMUC3. No significant effects were observed in the 5637 and SV-HUC-1 cells (Figure $3)$. In T24 cells, the growth inhibition rate after infection was only $10.766 \%$ at $100 \mathrm{MOI}$, but statistical significance was detected $(f(13,2)=6.713, p=0.012)$. Infected UMUC3 cells showed a moderate growth inhibition rate, which was 


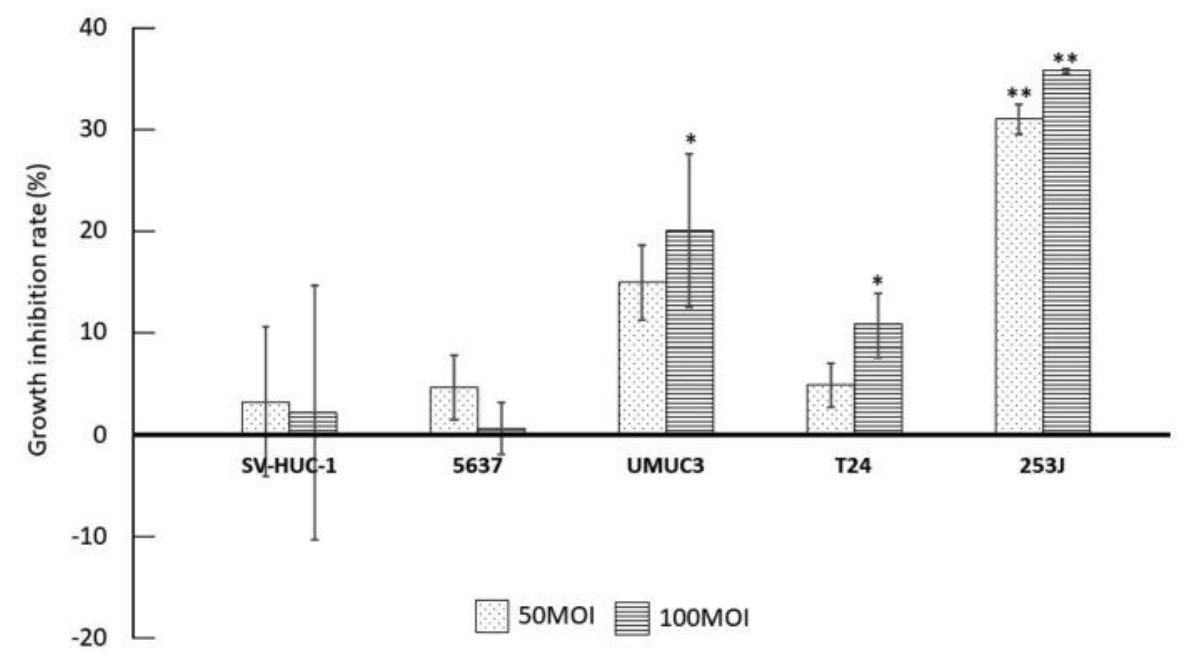

Figure 3. Cell growth inhibition rate of each cell line 96 h after p16 vector infection. Significant growth inhibition was observed in UMUC3, T24, and $253 \mathrm{~J}$ cells. The data represents the mean \pm S.E. of the mean percentage $(0 \%=$ cell inhibition rate of each uninfected cell line $) . N=3-5, * p<0.05, * * p<0.01$.

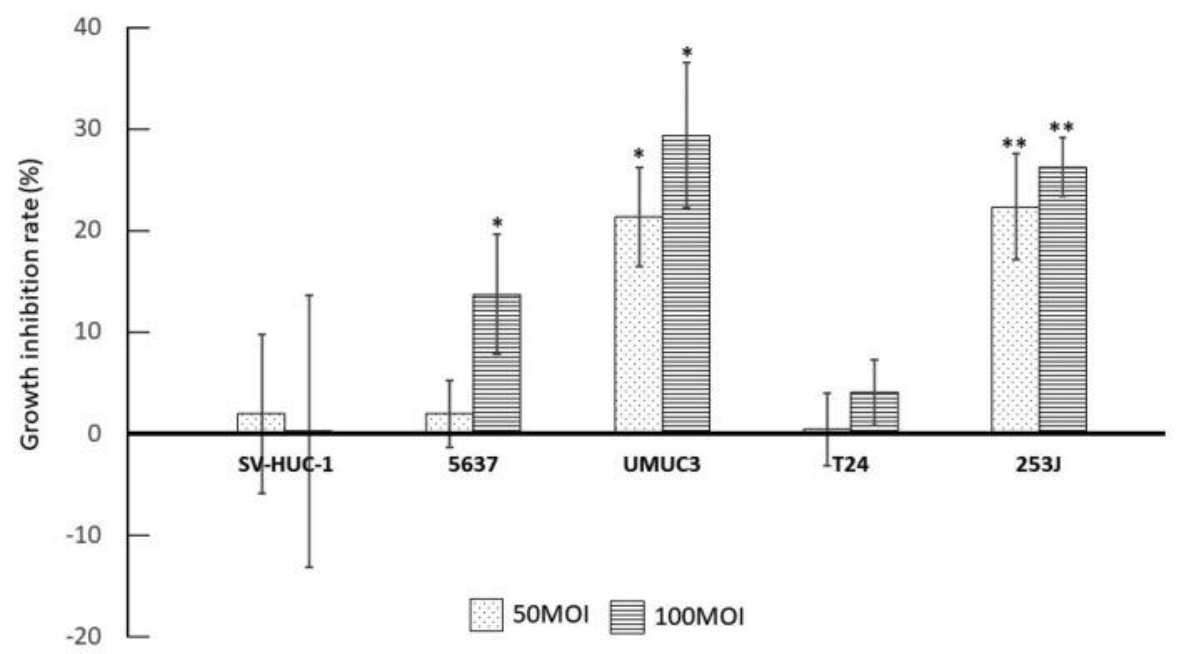

Figure 4. Cell growth inhibition rate of each cell line 96 h after PTEN vector infection. Significant growth inhibition was observed in 5637, UMUC3, and $253 \mathrm{~J}$ cells. The data represents the mean \pm S.E. of the mean percentage $(0 \%=$ cell inhibition rate of each uninfected cell line $) . N=3-5, * p<0.05, * * p<0.01$.

$20.014 \%$ at 100 MOI $(f(10,2)=6.234, p=0.023)$. The most notable effect of Lenti-p16 was observed in the 253J cells. The growth inhibition rates of the $253 \mathrm{~J}$ cells after infection were $30.987 \%$ at 50 MOI and $35.756 \%$ at 100 MOI $(f(10,2)=438.285, p<0.001)$.

Effect of Lenti-PTEN. Lenti-PTEN exhibited a significant effect on 5637, 253J, and UMUC3 cells, but did not affect T24 and SV-HUC-1 cells (Figure 4). Lenti-PTEN exhibited a moderate effect on the 5637 cells and a significant growth inhibition rate of $13.671 \%$ at 100 MOI $(f(14,2)=4.118$, $p=0.044)$. On the other hand, the UMUC3 and 253J cells demonstrated a higher sensitivity to the Lenti-PTEN vector when compared to the 5637 cells. The growth inhibition rates of the infected UMUC 3 cells were $21.327 \%$ at $50 \mathrm{MOI}$ and $29.345 \%$ at $100 \mathrm{MOI}(f(10,2)=11.241, p=0.005)$. In $253 \mathrm{~J}$ cells, the growth inhibition rates were $22.301 \%$ at $50 \mathrm{MOI}$ and $26.238 \%$ at $100 \mathrm{MOI}(f(9,2)=23.460, p<0.001)$.

\section{Discussion}

In this report, we noticed 3 typical tumor suppressor genes (p53, p16, and PTEN) and examined the effects of lentiviral vector-mediated transfection of the tumor suppressor genes in 
bladder cancer cells and normal human uroepithelial cells. Our aim was to develop an effective treatment for NMIBC without seriously deteriorating patient QOL.

In SV-HUC-1 cells (normal human uroepithelial cell line), significant growth inhibitory effects could not be observed after lentiviral vector infection. These results suggested that lentiviral vectors were a safe strategy for gene therapy. Currently, adenoviral vectors are widely used in the application of gene therapy. However, concerns have been raised regarding the safety of adenoviral vectors in clinical use because of their direct cytotoxic effects on target cells in vitro (25). Therefore, lentiviral vectors appear to be more suitable for cancer therapy. Although it is currently not possible to treat NMIBC without significantly deteriorating patient QOL, lentiviral vector-mediated gene therapy could possibly improve patient QOL in treating NMIBC in the future.

p53 mutation is observed in various human cancers, and several previous studies have shown the effectiveness of transfecting p53 into cancer cells $(26,27)$. Moreover, adenovirus-mediated p53 gene therapy has already been approved in China for the treatment of head and neck cancers (9). In this study, our lentiviral p53 vector, Lenti-p53, showed only a limited effect on T24 cells and no significant effect on the other bladder cancer cell lines (Figure 2). Mutation of the p53 gene has been reported in T24, 5637, and UMUC3 cell lines, but 253J contains the wild-type p53 (Table I) (28). Therefore, it is possible that the limited effect of the Lenti-p53 in our study is not directly related to the $p 53$ gene mutation. On the other hand, previous reports showed that the adenovirus-mediated p53 gene transfer suppressed the viability of the 5637 and 253J-BV cell lines (29), and knockdown of the mutant p53 induced apoptosis in the T24 cell line (30). These reports suggested that anti-tumor effects could be induced by simply restoring p53 abnormalities. Cumulatively, the poor efficacy of our p53 vector could be the result of the low in vitro infection efficiency of retroviruses, including lentiviral vectors $(31,32)$.

The Lenti-p16 vector showed significant growth inhibition in UMUC3, T24, and 253J cells, with the most significant inhibition being observed in the 253J cells (Figure 3). Homozygous deletion of the $p 16$ gene has been reported in the 253J cell line (28) and thus, our result appears to be reasonable. On the other hand, the 5637 cell line showed no significant effect when subjected to the Lenti-p16 vector. It has a wild-type $p 16$ gene (28); therefore, transfection of the pl6 gene may be useless. The status of the $p 16$ gene is unclear in the UMUC3 and T24 cell lines (Table I), but 100 MOI of Lenti-p16 demonstrated significant growth inhibition in UMUC3 and T24 cells. Understanding the status of the p16 gene will provide important clues about the anti-tumor effects of Lenti-p16. Therefore, it is necessary for us to examine the gene status of p16 in UMUC3 and T24 cells.
The Lenti-PTEN vector distinctly inhibited cell growth in the UMUC3 and 253J cells, and modestly inhibited the cell growth in the 5637 cells (Figure 4). PTEN gene mutation and deficient PTEN protein expression has already been reported in the UMUC3 cell line (33). However, the 253J and 5637 cell lines contain the wild-type PTEN gene (Table I). Therefore, it is possible that the cell inhibitory effect of Lenti-PTEN is not directly related to the mutation of the PTEN gene. PTEN gene mutation is believed to be rare in human bladder cancers (19, 20), but Lenti-PTEN showed significant cell growth inhibition, regardless of PTEN gene mutation. Therefore, we believe that Lenti-PTEN could be most useful in treating NMIBC.

On the other hand, the T24 cells exhibited no significant effect after being transfected with our PTEN vector. The T24 cell line has a mutated PTEN gene, but PTEN protein expression has been reported (33). The function of the transfected PTEN gene is thought to be inhibited by the expression of the mutated PTEN protein in T24 cells.

In this study, lentivirus-mediated transfection of tumor suppressor genes demonstrated prospective anti-tumor effects on bladder cancer cell lines. Moreover, lentiviral vectors also showed high safety while transfecting normal cells. Although BCG therapy is thought to be the most effective treatment for NMIBC, its strong adverse effects result in significantly reducing patient QOL. Virotherapy using lentivirus may be a possible solution to effectively treat NMIBC without seriously deteriorating patient QOL.

\section{Conflicts of Interest}

The Authors have no potential conflicts of interest to disclose with regard to this study.

\section{Acknowledgements}

The Authors wish to thank Satoko Kodama for her help in the completion of the article.

\section{References}

1 Leopardo D, Cecere SC, Di Napoli M, Cavaliere C, Pisano C, Striano S, Marra L, Menna L, Claudio L, Perdonà S, Setola S, Berretta M, Franco R, Tambaro R, Pignata S and Facchini G: Intravesical chemo-immunotherapy in non-muscle invasive bladder cancer. Eur Rev Med Pharmacol Sci 17: 2145-2158, 2013.

2 Cancer Registry and Statistics. Cancer Info on Service, National Cancer Center, Japan, 2016.

3 Herr HW and Morales A: History of bacillus Calmette-Guerin and bladder cancer: An immunotherapy success story. J Urol 179: 5356, 2008.

4 Takao Y, Masumoto N, Takasu Y, Ohtsuki H, Wadagaki F, Kajio K, Yoshimoto T and Iwakawa S: Comparison of subjective adverse effects, accomplishment rate and achievement rate during intravesical instillation therapy using BCG (Bacillus CalmetteGuerin) or pirarubicin for bladder cancer patients at Kawanishi City General Hospital Japan. J Pharm Health Care Sci 32: 235-241, 2006. 
5 Chester JD, Kennedy W, Hall GD, Selby PJ and Knowles MA: Adenovirus-mediated gene therapy for bladder cancer: efficient gene delivery to normal and malignant human urothelial cells in vitro and ex vivo. Gene Therapy 10: 172-179, 2003.

6 Tan J, Zeng Q, Jiang XZ, He LY, Wang JR, Yao K and Wang $\mathrm{CH}$ : Apoptosis of bladder transitional cell carcinoma T24 cells induced by adenovirus-mediated inducible nitric oxide synthase gene transfection. Chin J Cancer Res 25: 593-599, 2013.

7 Gotoh A, Nagaya H, Kanno T, Tagawa M and Nishizaki T: Fiber-substituted conditionally replicating adenovirus Ad5F35 induces oncolysis of human bladder cancer cells in in vitro analysis. Urology 81: 920.e7-920.e11, 2013.

8 Schroeder JC, Conway K, Li Y, Mistry K, Bell DA and Taylor JA: p53 mutations in bladder cancer: evidence for exogenous versus endogenous risk factors. Cancer Res 63: 7530-7538, 2003.

$9 \mathrm{Li} \mathrm{Y,} \mathrm{Li} \mathrm{B,} \mathrm{Li} \mathrm{CJ} \mathrm{and} \mathrm{Li} \mathrm{LJ:} \mathrm{Key} \mathrm{points} \mathrm{of} \mathrm{basic} \mathrm{theories} \mathrm{and}$ clinical practice in rAd-p53 (Gendicine ${ }^{\mathrm{TM}}$ ) gene therapy for solid malignant tumors. Expert Opin Biol Ther 15: 437-454, 2015.

10 Krishnamurthy J, Torrice C, Ramsey MR, Kovalev GI, AlRegaiey K, Su L and Sharpless NE: Ink4a/Arf expression is a biomarker of aging. J Clin Invest 114: 1299-1307, 2004.

11 Ressler S, Bartkova J, Niederegger H, Bartek J, ScharffetterKochanek K, Jansen-Dürr P and Wlaschek M: p16/INK4A is a robust in vivo biomarker of cellular aging in human skin. Aging Cell 5: 379-389, 2006.

12 Loughran O, Malliri A, Owens D, Gallimore PH, Stanley MA, Ozanne B, Frame MC and Parkinson EK: Association of CDKN2A/p16INK4A with human head and neck keratinocyte replicative senescence: relationship of dysfunction to immortality and neoplasia. Oncogene 13: 561-568, 1996.

13 Liggett WH Jr and Sidransky D: Role of the p16 tumor suppressor gene in cancer. J Clin Oncol 16: 1197-1206, 1998.

14 Liaw D, Marsh DJ, Li J, Dahia PL, Wang SI, Zheng Z, Bose S, Call KM, Tsou HC, Peacocke M, Eng C and Parsons R: Germline mutations of the PTEN gene in Cowden disease, an inherited breast and thyroid cancer syndrome. Nat Genet 16: 64-67, 1997.

15 Stjernström A, Karlsson C, Fernandez OJ, Söderkvist P, Karlsson MG and Thunell LK: Alterations of INPP4B, PIK3CA and pAkt of the PI3K pathway are associated with squamous cell carcinoma of the lung. Cancer Med 3: 337-348, 2014.

16 Wise HM, Hermida MA and Leslie NR: Prostate cancer, PI3K, PTEN and prognosis. Clin Sci (Lond) 131: 197-210, 2017.

17 Wen YG, Wang Q, Zhou CZ, Qiu GQ, Peng ZH and Tang HM: Mutation analysis of tumor suppressor gene PTEN in patients with gastric carcinomas and its impact on PI3K/AKT pathway. Oncol Rep 24: 89-95, 2010.

18 Maehama T and Dixon JE: The tumor suppressor, PTEN/MMAC1, dephosphorylates the lipid second messenger, phosphatidylinositol 3,4,5-trisphosphate. J Biol Chem 29: 13375-13378, 1998.

19 Cairns P, Evron E, Okami K, Halachmi N, Esteller M, Herman JG, Bose S, Wang SI, Parsons R and Sidransky D: Point mutation and homozygous deletion of PTEN/MMAC1 in primary bladder cancers. Oncogene 16: 3215-3218, 1998.

20 Mashhadi R, Pourmand G, Mehrsai A, Pakdel S, Dialameh H, Ahmadi A, Salem S, Salimi E and Mahboubi R: Effect of PTEN gene mutations and environmental risk factors on the progression and prognosis of bladder cancer. Iran $\mathrm{J}$ Public Health 43: 56-61, 2014.
21 Tanaka $\mathrm{M}$ and Grossman HB: In vivo gene therapy of human bladder cancer with PTEN suppresses tumor growth, downregulates phosphorylated Akt, and increases sensitivity to doxorubicin. Gene Ther 10: 1636-1642, 2003.

22 Davies MA, Kim SJ, Parikh NU, Dong Z, Bucana CD and Gallick GE: Adenoviral-mediated expression of MMAC/PTEN inhibits proliferation and metastasis of human prostate cancer cells. Clin Cancer Res 8: 1904-1914, 2002.

23 Berggren WT, Lutz M and Modesto V: General Spinfection Protocol. StemBook, 2012. Available from: http:// www.stembook.org/sites/default/files/protocols/GeneralSpinfection-Protocol.pdf [last accessed on February 6, 2018].

24 Nagaya H, Gotoh A, Kanno T and Nishizaki T: A3 adenosine receptor mediates apoptosis in in vitro RCC4-VHL human renal cancer cells by up-regulating AMID expression. J Urol 189: 321328, 2013.

25 Zheng C, Goldsmith CM, O'Connell BC and Baum BJ: Adenoviral vector cytotoxicity depends in part on the transgene encoded. Biochem Biophys Res Commun 274: 761-771, 2000.

26 Fujiwara T, Grimm EA, Mukhopadhyay T, Zhang WW, OwenSchaub LB and Roth JA: Induction of chemosensitivity in human lung cancer cells in vivo by adenovirus-mediated transfer of the wild-type p53 gene. Cancer Res 54: 2287-2291, 1994.

27 Ohashi M, Kanai F, Ueno H, Tanaka T, Tateishi K, Kawakami T, Koike Y, Ikenoue T, Shiratori Y, Hamada H and Omata M: Adenovirus mediated p53 tumour suppressor gene therapy for human gastric cancer cells in vitro and in vivo. Gut 44: 366-371, 1999.

28 Earl J, Rico D, Carrillo-de-Santa-Pau E, Rodríguez-Santiago B, Méndez-Pertuz M, Auer H, Gómez G, Grossman HB, Pisano DG, Schulz WA, Pérez-Jurado LA, Carrato A, Theodorescu D, Chanock S, Valencia A and Real FX: The UBC-40 Urothelial Bladder Cancer cell line index: a genomic resource for functional studies. BMC Genomics 16: 403, 2015.

29 Pagliaro LC, Keyhani A, Liu B, Perrotte P, Wilson D and Dinney CP: Adenoviral p53 gene transfer in human bladder cancer cell lines: cytotoxicity and synergy with cisplatin. Urol Oncol 21: 456-462, 2003.

30 Zhu HB, Yang K, Xie YQ, Lin YW, Mao QQ and Xie LP: Silencing of mutant $\mathrm{p} 53$ by siRNA induces cell cycle arrest and apoptosis in human bladder cancer cells. World J Surg Oncol 28: 11-22, 2013.

31 Davis HE, Morgan JR and Yarmush ML: Polybrene increases retrovirus gene transfer efficiency by enhancing receptorindependent virus adsorption on target cell membranes. Biophys Chem 97: 159-172, 2002.

32 Davis HE, Rosinski M, Morgan JR and Yarmush ML: Charged polymers modulate retrovirus transduction via membrane charge neutralization and virus aggregation. Biophys J 86: 1234-1242, 2004.

33 Platt FM, Hurst CD, Taylor CF, Gregory WM, Harnden P and Knowles MA: Spectrum of phosphatidylinositol 3-kinase pathway gene alterations in bladder cancer. Clin Cancer Res 15: 6008-6017, 2009.

Received January 18, 2018

Revised February 5, 2018

Accepted February 6, 2018 